\section{MARCOS REGULATÓRIOS E AS IMPLICAÇÕES NA ORGANIZAÇÃO DO CURRÍCULO PARA EDUCAÇÃO INFANTIL BRASILEIRA}

\author{
REGULATORY FRAMEWORKS AND THE IMPLICATIONS IN THE ORGANIZATION OF THE \\ CURRICULUM FOR BRAZILIAN CHILD EDUCATION
}

\author{
Joseane da Silva Miller Rodrigues \\ Noemi Boer ${ }^{2}$ \\ Fernanda Marquezan ${ }^{3}$
}

\begin{abstract}
Resumo: No presente artigo, investiga-se como ocorreu o processo de regulamentação da Educação Infantil no contexto brasileiro e as implicações que a legislação gerou na organização do currículo para esse nível de ensino. $O$ estudo caracteriza-se como uma revisão bibliográfica descritiva, em que foram consultados autores e documentos oficiais relativos à Educação Infantil. Considera-se a importância das regulamentações, no campo educacional, e seus atravessamentos na construção do saber de docentes que atuam nessa etapa da educação básica. Conclui-se que os marcos regulatórios os quais normatizam a Educação Infantil servem como ações de seu fortalecimento e devem contribuir para efetivar o direito da criança à educação na primeira infância, promovendo sua inclusão social e democratizando o acesso a um ensino com qualidade.
\end{abstract}

Palavras-chave: Bases Legais. Creche. Pré-escola. Currículo.

\section{INTRODUÇÃO}

Neste artigo, investiga-se como ocorreu o processo de regulamentação da Educação Infantil, no contexto brasileiro, e as implicações que a legislação causou na organização do currículo para esse nível de ensino. Logo, a pesquisa se justifica pela importância dos marcos regulatórios, no campo da Educação Infantil, bem como seus atravessamentos na construção do saber dos docentes que atuam nessa etapa da educação básica.

O presente trabalho é um recorte da dissertação da primeira autora, em que foi investigada $A$ atuação docente na Educação Infantil. $\mathrm{O}$ texto faz parte de uma seção na qual se objetiva descrever a

\footnotetext{
${ }^{1}$ Professora de Educação Infantil e Mestre em Ensino de Humanidades e Linguagens pela Universidade Franciscana. E-mail: joseane.miller@gmail.com. Orcid: https://orcid.org/0000-0002-4689-2580.

2 Professora do Programa de Pós-Graduação Ensino Científico e Tecnológico da Universidade Regional Integrada do Alto Uruguai e das Missões e do Mestrado em Ensino de Humanidades e Linguagens do Centro Universitário Franciscano. E-mail: noemiboer@gmail.com. Orcid: https://orcid.org/0000-0002-3745-2196.

3 Professora Adjunta da Universidade Franciscana (UFN), docente do Curso de Mestrado em Ensino de Humanidades e Linguagens (MEHL) e do Curso de Pedagogia. Coordenadora do PIBID Pedagogia. Membro do grupo de pesquisa Formação de Professores e Docência - FORPRODOC (UFN) e do Centro de Estudos em Educação Superior (PUCRS). E-mail: marquezanfernanda@gmail.com. Orcid: https://orcid.org/0000-0002-8009-9105.
}

\begin{abstract}
This article investigates as the regulatory process of early childhood education in the Brazilian
context and the implications these have generated in the Organization of the curriculum for this level of bibliographical review in which they were consulted authors and official documents relating to early of regulations in the educational field and their crossings in the construction of knowledge of is concluded that the regulatory framework to regulate them, the early childhood education, serve to implement the right of the child to early childhood education, promoting your social inclusion and
\end{abstract} Keywords: legal Bases. Daycare. Preschool. Curriculum. 
gênese, o histórico e as concepções de Educação Infantil presentes nas políticas públicas do país.

Para atender a esses objetivos, optou-se por uma revisão bibliográfica descritiva. As fontes de pesquisa se trata de documentos reguladores da Educação Infantil, livros e artigos publicados em periódicos e em anais de eventos. Desse modo, num primeiro momento, apresenta-se uma breve contextualização histórica referente às bases legais da Educação Infantil Brasileira, relembrando as Diretrizes e Bases da Educação Nacional, Lei n 4.024 (BRASIL, 1961) e a Reforma do Ensino de $1^{\circ}$ e $2^{\circ}$ Graus, Lei $n^{\circ} 5.692$ (BRASIL, 1971). Na sequência, são retomadas a Constituição Federal de 1988 (BRASIL, 1988) e a Lei $n^{\circ} 9.394$ (BRASIL, 1996), uma vez que são documentos fundamentais no processo de inserção da Educação Infantil na Política Nacional da Educação. Posteriormente, abordam-se as políticas curriculares para Educação Infantil com base nos seguintes documentos: Referencial Curricular Nacional para a Educação Infantil (BRASIL, 1998); Diretrizes Curriculares Nacionais para Educação Infantil (BRASIL, 2009), Planos Nacionais de Educação (BRASIL, 2011; 2014) e Base Nacional Comum Curricular (BRASIL, 2017).

Considerando-se o direito de acesso à creche, na faixa etária de o a 3 anos, é necessário que haja uma equidade entre os conteúdos que são trabalhados, nas instituições de Educação Infantil, e as necessidades da criança. É imprescindível o respeito à integralidade da criança, considerando-se a realidade sociocultural da família e a cultura da comunidade em que a instituição está inserida. Nessa linha de raciocino, cabe à escola selecionar conteúdos os quais ampliem o universo cultural da criança na perspectiva de sua formação humana.

Em vista desse entendimento, são apresentados, neste texto, diferentes concepções de currículo na Educação Infantil. Destaca-se que o currículo tem gerado controvérsias entre professores de creches, pré-escolas e demais profissionais da educação. Observa-se que uma parcela de profissionais defende a importância da organização curricular na Educação Infantil. No contraponto, outra parcela de profissionais acredita que a Educação Infantil não deveria se envolver com as questões de currículo pelo fato de que ele está associado à escolarização, à disciplina e aos conteúdos escolares próprios do Ensino Fundamental e Médio.

\section{MARCOS REGULATÓRIOS DA EDUCAÇÃO INFANTIL NO BRASIL}

A contextualização histórica, referente aos marcos regulatórios da Educação Infantil no Brasil, compreende diversas legislações, dentre elas: a Constituição Federal de 1988 que preconiza, em seu Art. 208, "o atendimento em creches e pré-escola às crianças de zero a seis anos de idade" (BRASIL, 1988); o Estatuto da Criança e do Adolescente (ECA), Lei $n^{\circ} 8.069 / 90$, o qual atribui, ao Poder Público, prioridade na efetivação dos direitos das crianças (BRASIL, 1990); a Lei de Diretrizes e Bases da Educação Nacional, Lei $n^{\circ}$ 9.394/96, que define a Educação Infantil como um direito da criança e um dever do Estado (BRASIL, 1996a); o Plano Nacional de Educação (PNE), para o período 2001-2011, lei n 10.172/2001 (BRASIL, 2001), e o PNE, para o período 2014-2024, lei $n^{\circ}$ 13.005/14 (BRASIL, 2014). Essas duas últimas legislações estabelecem diretrizes, objetivos e metas, por um período de dez anos, para as políticas educacionais, em todos os níveis e modalidades de ensino.

Em relação à primeira a primeira Lei de Diretrizes e Bases da Educação Nacional (LDB), Lei $n^{\circ}$ 4.024/1961 (BRASIL, 1961), cabe destacar que, em 1948, o ministro Clemente Mariani apresentou o anteprojeto dessa lei. Esse anteprojeto estava baseado em um trabalho confiado a educadores, sob orientação de Lourenço Filho. Além das escolas novistas, participaram da elaboração dele católicos tradicionalistas, como o padre Leonel Franca e Alceu Amoroso Lima. O percurso desse projeto foi longo e tumultuado, estendeu-se até 1961, data da sua promulgação (ROMANELLI, 2003). Desse modo, foram necessários treze anos de discussões para que Lei $n^{\circ}$ 4.024/1961 fosse promulgada após o dinamismo do contexto sociopolítico e econômico do início da década de 1960. A referida lei se refere discretamente à Educação Infantil, como: "Ensino pré-primário, composto de escolas maternais e jardins de infância" (ROMANELLI, 2003, p. 181). Contudo, não assegurou o fortalecimento de práticas educativas adequadas às características das crianças pequenas e, após o golpe militar de 1964, essa diretriz foi abandonada.

Em um segundo momento, pode-se destacar a Lei $n^{\circ}$ 5.692/1971 (BRASIL, 1971), que estabeleceu a Reforma do Ensino de $1^{\circ}$ e $2^{\circ}$ Graus. O espírito dessa lei primou pelo tecnicismo, e ela não contemplou, em seu texto, a educação de crianças menores de sete anos. Apenas o Art. 19 menciona a Educação Infantil: 
Art. 19. Para o ingresso no ensino de $1^{\circ}$ grau, deverá o aluno ter a idade mínima de sete anos.

$\S 1^{\circ}$ As normas de cada sistema disporão sobre a possibilidade de ingresso no ensino de primeiro grau de alunos com menos de sete anos de idade.

$\S 2^{\circ}$ Os sistemas de ensino velarão para que as crianças de idade inferior a sete anos recebam conveniente educação em escolas maternais, jardins de infância e instituições equivalentes (BRASIL, 1971).

Consoante a isso, constata-se a omissão do Estado na efetivação da Educação Infantil, ficando sua prescrição em um único parágrafo dentro do Art. 19. Esse faz menção aos sistemas de ensino ou instituições equivalentes, que deverão atender crianças menores de sete anos. O termo "velarão" representava a concepção implícita no texto da lei, pressupondo uma educação simbólica, paliativa e coadjuvante, pois a Educação Infantil não contribuiria no contexto histórico da época, de forma imediata, no processo de industrialização, mas sim o ensino de segundo grau (ROMANELLI, 2003).

Nessa perspectiva, não se pode deixar de considerar que tal lei foi gestada em um período em que ainda não eram sentidas as consequências do Ato Institucional n ${ }^{\circ} 5$ (Al5) de 1964, o qual instituiu a censura à imprensa, à educação e à cultura (BRASIL, 1968).

As palavras de ordem, nesse período, eram produção e produtividade. De acordo com Fazenda (1988), elas emergem da produção do sistema educacional com relação ao número de profissionais qualificados e de mão-de-obra nos setores industriais e rurais, necessários ao desenvolvimento industrial.

Assim, predominava uma linguagem científico-tecnocrata, da antecipação da formação do trabalhador, que ganha contornos mais definidos no ensino fundamental e médio, em que predominava uma proposta que deixava, em segundo plano, a formação do indivíduo e ganhava força a formação para a ascensão social, com uma larga ampliação do ensino profissionalizante. Embora não estivesse claro, ao menos na letra da lei, qual o papel da Educação Infantil - à época educação pré-escolar - nota-se uma clara influência nas experiências que já existiam nesse período no Brasil: uma forte preocupação da Educação Infantil com a prevenção de um futuro fracasso escolar, ou seja, a pré-escola preparatória (FAZENDA, 1988).

Conforme os autores consultados, a ideia da pré-escola preparatória à educação escolar foi sendo edificada, nos Estados Unidos e na Europa, no período pós $2^{\text {a }}$ guerra mundial. Dadas as condições adversas em que se encontravam as famílias e o número elevado de crianças órfãs, propunha-se uma educação compensatória às deficiências culturais, linguísticas e afetivas das crianças, como se percebe no excerto:

É importante realçar: 1. o preconceito com que as crianças das classes populares eram encaradas; 2 . O escamoteamento ideológico que acobertava a divisão da sociedade em classes; 3. que a ideia de preparação se vinculava diretamente à compensação das "carências" infantis, através do adestramento das crianças nas habilidades e conhecimentos que não possuam (ABRAMOVAY; KRAMER, 1984, p.30).

Nessa linha de pensamento, o início da década de 1980 foi marcado por discussões e por mobilizações acerca do papel das instituições de Educação Infantil. Por um lado, o meio acadêmico fazia críticas às teorias de privação cultural e ao caráter compensatório ou preparatório da pré-escola. Por outro lado, os movimentos sociais organizados pela sociedade civil e pelos profissionais da área defendiam o que entendiam por caráter educacional ou pedagógico para essas instituições, contrapondo-se ao que, então, considerava-se como meramente assistencial (ABRAMOVAY; KRAMER, 1984; CORREA, 2002).

Participaram, dessas mobilizações, além dos atores sociais tradicionais, o Movimento de Mulheres e o Criança Pró-Constituinte. Essas entidades elaboraram uma proposta para a Constituição Federal de 1988, reconhecendo a Educação Infantil como uma extensão do direito universal à educação de crianças menores de sete anos e um direito de homens e mulheres trabalhadores terem seus filhos pequenos cuidados e educados em creches e pré-escolas (CORRÊA, 2002). Esses direitos foram contemplados na 
Constituição Federal de 1988, tanto no capítulo da educação quanto na seção que trata dos direitos à assistência social (BRASIL, 1988). Por conta disso, a Constituição de 1988 foi a primeira, na história do Brasil, a afirmar a cidadania da criança. Isso se deu ao estabelecer que toda criança é sujeita de direitos (CORRÊA, 2002).

Decorrente dos preceitos constitucionais de 1988, o primeiro projeto da nova Lei de Diretrizes e Bases da Educação Nacional (LDBEN), Lei n 9.394/1996, resultou em amplo debate, não só na Câmara, mas também foi ouvida, durante sua elaboração, a sociedade civil, sobretudo no Fórum Nacional em Defesa da Escola Pública. Durante esse, mobilizaram-se diferentes setores educacionais, universidades, instituições de pesquisa, sindicatos de educadores e organizações não governamentais. $O$ objetivo dessa mobilização foi a preparação de um contexto para aprovação da nova LDBN, sendo sancionada em 20 de dezembro de 1996.

A referida lei trouxe contribuições importantes para a Educação Infantil. Os Art. $11^{\circ}, 12^{\circ}$ e $13^{\circ}$ estabelecem que compete aos municípios oferecer Educação Infantil, em creches e pré-escolas, sendo que cabe aos próprios estabelecimentos de ensino a elaboração e execução da proposta pedagógica. Desse modo, nos termos da lei, os docentes devem participar da elaboração da proposta pedagógica de cada estabelecimento (BRASIL, 1996a).

O Art. $18^{\circ}$ da LDBEN especifica a organização das instituições de Educação Infantil como públicas ou privadas, e afirma que ambas fazem parte do sistema municipal de ensino. Os Art. $29^{\circ}$ e $30^{\circ}$ situam a Educação Infantil como primeira etapa da educação básica, tendo, como finalidade, o desenvolvimento integral da criança até cinco anos, nos seguintes aspectos: físico, psicológico, intelectual e social. Sua oferta se dará em creches, para crianças de até três anos de idade, e em pré-escolas para crianças de quatro e cinco anos (BRASIL, 1996a).

O mesmo documento, em seu Art. $62^{\circ}$, estabelece que a formação de docentes, com o intuito de atuar na educação básica, far-se-á em nível superior, em curso de licenciatura plena, considerada como formação mínima para o exercício do magistério na Educação Infantil. Já nos cinco primeiros anos do ensino fundamental, a formação mínima é a em nível médio, na modalidade normal (BRASIL, 1996a).

Desse modo, a LDBN demonstra um estreitamento na relação entre cuidar e educar, na medida em que concebe a criança como um ser integral e específico, que merece atenção em seus aspectos biopsicossocial. Ao mesmo tempo, essa lei determina que os profissionais que atuarem nesse nível de ensino devem ter formação em nível superior, retificando o assistencialismo e a compensação que, durante anos, as crianças pobres estiveram confiadas (BRASIL, 1996a).

É importante frisar que, no início da década de 1990, as Organizações Internacionais entraram em cena novamente, via Banco Mundial, recuperando "[...] propostas equivalentes às da UNESCO e UNICEF dos anos 1970, desconsiderando o pequeno percurso brasileiro na construção de uma Educação Infantil democrática" (ROSEMBERG, 2002, p. 11).

Para o contexto educacional, o Banco Mundial trouxe fortes influências no que tange à Educação Infantil, porque incrementou o financiamento dessa por meio de empréstimos destinados a duas linhas de ação: uma para o pré-escolar, numa estratégia preventiva do fracasso escolar, mais do que habilitadora do êxito escolar, denominada educação inicial. A outra linha de ação se trata de uma específica para crianças pequenas, geralmente denominada Desenvolvimento Infantil, expressão que tanto pode significar uma ampliação do enfoque para saúde, nutrição e educação, quanto pode significar o privilegiamento de modelos informais de atendimento da primeira infância (ROSEMBERG, 2002).

Em 1998, foi organizado, pelo Ministério de Educação e Cultura (MEC), contando com a contribuição de especialistas e de representantes dos Conselhos de Educação de todos os Estados, o documento Subsídios para o Credenciamento e Funcionamento das Instituições de Educação Infantil (BRASIL, 1998a), o qual contribuiu para a formação de normas e de diretrizes relacionadas à Educação Infantil. Concomitantemente, foi realizada, pelo MEC, uma pesquisa para serem conhecidas as propostas pedagógico-curriculares adotadas em todo o país, assim como os princípios que norteavam a prática cotidiana das instituições. Com base nos dados decorrentes desse estudo, o MEC elaborou o Referencial Curricular Nacional para a Educação Infantil (RCNEI), com o propósito de oferecer uma base nacional 
ISSN $1983-1579$

Doi: 10.22478/ufpb.1983-1579.2020v13n1.41599

http://periodicos.ufpb.br/ojs2/index.php

comum para os currículos, apesar de não ser obrigatória (BRASIL, 1998b).

Nesse viés, é possível dizer que o RCNEI representa um avanço, nessa etapa educacional, ao buscar soluções educativas para a superação, de um lado, da tradição assistencialista das creches e, por outro lado, da marca de antecipação da escolaridade nas pré-escolas. Desse modo, o referencial foi concebido de maneira a servir como um guia de reflexão de cunho educacional acerca dos objetivos, dos conteúdos e das orientações didáticas para os profissionais que atuam diretamente com crianças de zero a seis anos ${ }^{4}$ e tem, como base, o respeito aos estilos pedagógicos e à diversidade cultural brasileira.

É importante destacar que o RCNEI não possui peso de lei, mas, devido à sua ampla divulgação, acabou por se tornar um guia para a maior parte das escolas e pré-escolas brasileiras. Posteriormente, a homologação da Resolução n5/2009 definiu as Diretrizes Curriculares Nacionais para a Educação Infantil (DCNEI). A organização curricular e pedagógica, dessa etapa do ensino, então, passou a ter obrigatoriedade de seguir as orientações do referido documento (BRASIL, 2010).

Algumas críticas, referentes às RCNEI, foram encontradas na literatura consultada. Uma delas diz respeito à falta de flexibilidade nas formulações locais, desconsiderando as características do contexto em que a criança está inserida. O caráter homogêneo das RCNEI mostra como suas intenções vão além da formulação de um guia, visto que, por vezes, defendem a elaboração de uma prática homogeneizante, frente a uma realidade desigual de nosso país, e se constitui como um currículo de fato (AQUINO; VASCONCELLOS, 2005).

O referido documento se divide em três diferentes livros: Introdução, Formação pessoal e social e Conhecimento de mundo. No primeiro, denominado Introdução, é apresentada a realidade brasileira das creches e pré-escolas, bem como concepções de ser criança, sobre o cuidar e o educar, o perfil do profissional que trabalha com Educação Infantil. Também localiza o leitor sobre como é a organização do referencial e expõe orientações, para as instituições, no espaço físico e na elaboração do projeto educativo (BRASIL, 1998b).

O segundo livro, denominado Formação pessoal e social, aborda as questões sociais e a construção da autonomia das crianças dentro das instituições de Educação Infantil, contemplando suas aprendizagens, nas diferentes faixas etárias, orientando sobre os conteúdos que podem ser trabalhados. Nele, igualmente, são apresentadas orientações gerais para que os professores possam ler e se inteirar de vários aspectos essenciais que precisam estar presentes no cotidiano da sala de aula (BRASIL, 1998c).

$\mathrm{E}$, finalmente, no terceiro livro, Conhecimentos de mundo, são explorados seis eixos temáticos que podem ser trabalhados com as crianças. Essa obra apresenta uma série de propostas de atividades, as quais podem ser realizadas com as crianças e que visam ao desenvolvimento de algumas áreas, como: movimento, música, artes visuais, linguagem oral e escrita e, por fim, natureza e sociedade (BRASIL, 1998d). Na contramão das propostas do RCNEl, observa-se, na contemporaneidade, um retorno às práticas espontaneístas. Por consequência do discurso de valorização do brincar e das interações entre crianças ou entre criança e professor, para estimular o desenvolvimento infantil, criou-se uma ideia errônea de que a função do professor infantil é só “deixar brincar”. Percebe-se, dessa maneira, a falta de reflexão e de intencionalidade educativa, uma vez que a aprendizagem só ocorre se o professor tiver uma intencionalidade e souber em que lugar quer chegar com o ensino.

Nesse sentido, a partir da Constituição Federal de 1988 e da LDBN (BRASIL, 1996a), a inclusão de creches e pré-escolas, no sistema de ensino, provocou avanços para a Educação Infantil, como a elevação do nível de formação de seus docentes e a concepção de criança como sujeito de direitos, que necessita se desenvolver biopsicossocialmente. Entretanto, constata-se a necessidade de instrumentos que articulem o trabalho pedagógico ao longo dessas etapas do desenvolvimento da criança.

O Plano Nacional de Educação (PNE), para o período 2001-2010, instituído por meio da Lei n 10.172,

${ }^{4}$ De acordo com a Lei $n^{\circ}$ 12.796/2013, Art. 29, a referida idade, foi alterada de zero a cinco anos e onze meses (BRASIL, 2013). 
de 09 de janeiro de 2001, estabeleceu diretrizes, objetivos e metas de curto, médio e longo prazos, para a educação, na década citada. No diagnóstico da Educação Infantil inserido nesse Plano, já estavam presentes os argumentos econômicos, de necessidade social e do direito ao cuidado e à educação, a partir do nascimento, para justificar a expansão dessa, oferta a despeito de não ter caráter obrigatório (BRASIL, 2001).

Entre os temas destacados, havia, no PNE 2001-2010, a preocupação de assegurar, em todos os municípios, recursos financeiros para a Educação Infantil, a qual, muitas vezes, era relegada em função de investimentos para dar cumprimento ao ensino obrigatório. Assim, a meta 18 do PNE determina que sejam destinados os $10 \%$ dos recursos de manutenção e de desenvolvimento do ensino não vinculados ao Fundo de Manutenção e Desenvolvimento do Ensino Fundamental e de Valorização do Magistério (FUNDEF), de forma prioritária, para a Educação Infantil, além de outros disponíveis a cada ente municipal (BRASIL, 2001).

As Diretrizes Curriculares Nacionais da Educação Infantil (DCNEI), aprovadas pelo Conselho Nacional de Educação em 2009, conforme Parecer CNE/CEB n²0/09 e Resolução CNE/CEB no 05/09, (BRASIL, 2010), representam uma oportunidade para se pensar como e em que direção atuar junto à criança. A partir de determinados parâmetros, as DCNEI articulam os processos de ensino e de aprendizagem na Educação Infantil, de acordo com o que é especificado na organização do currículo na Educação Infantil.

O avanço identificado nas DCNEl é que esse documento estabelece a obrigatoriedade de organizar propostas curriculares de caráter heterogêneo, que atendam às particularidades do contexto da criança (BRASIL, 2010).

No ano de 2013, entra em cena a Lei $n^{\circ} 12.796$ que altera a Lei $n^{\circ}$ 9.394/96 para dispor sobre a formação dos profissionais da educação. Essa também dá outras providências (BRASIL, 2013). Referente à Educação Infantil, os Arts. $6^{\circ}, 29^{\circ}, 30^{\circ}$ e $31^{\circ}$ da LDBEN (BRASIL, 1996a) foram atualizados, conforme especificado a seguir:

O Art. $6^{\circ}$ dispõe que "É dever dos pais ou responsáveis efetuar a matrícula das crianças na educação básica a partir dos 4 (quatro) anos de idade" (BRASIL, 2013,). Já o Art. $29^{\circ}$ declara que "A Educação Infantil, primeira etapa da educação básica, tem, como finalidade, o desenvolvimento integral da criança de até 5 (cinco) anos, em seus aspectos físico, psicológico, intelectual e social, complementando a ação da família e da comunidade".

Já o Art. $30^{\circ}$, dispõe que a Educação Infantil será oferecida, em creches ou em entidades equivalentes, para crianças de até três anos de idade; e pré-escolas, para as crianças de 4 (quatro) a 5 (cinco) anos de idade (BRASIL, 2013).

Quanto ao Art. $31^{\circ}$, nele é determinado que a Educação Infantil deve ser organizada segundo as seguintes regras comuns:

I - Avaliação mediante acompanhamento e registro do desenvolvimento das crianças, sem o objetivo de promoção, mesmo para o acesso ao ensino fundamental;

II - Carga horária mínima anual de 800 (oitocentas) horas, distribuída por um mínimo de 200 (duzentos) dias de trabalho educacional;

III - Atendimento à criança de, no mínimo, 4 (quatro) horas diárias para o turno parcial e de 7 (sete) horas para a jornada integral;

IV - Controle de frequência pela instituição de educação pré-escolar, exigida a frequência mínima de $60 \%$ (sessenta por cento) do total de horas;

$V$ - Expedição de documentação que permita atestar os processos de desenvolvimento e aprendizagem da criança (BRASIL, 2013).

O Plano Nacional de Educação, para o período de 2014-2024, foi instituído pela Lei $n^{\circ} 13.005$, de 25 de junho de 2014. É um instrumento de planejamento do Estado democrático de direito, o qual orienta a 
execução e o aprimoramento de políticas públicas do setor. Nesse novo texto, PNE, fruto de amplos debates entre diversos atores sociais e o poder público, estão definidos os objetivos e as metas para o ensino em todos os níveis, infantil, básico e superior, a serem executados nos próximos dez anos. Nele, já estava em vigência o Fundo de Manutenção e Desenvolvimento da Educação Básica e de Valorização dos Profissionais da Educação, aprovado pela Emenda Constitucional $n^{\circ} 53$, que passou a financiar toda a educação básica (BRASIL, 2014).

No referido plano, são apresentadas vinte metas. As que se referem à Educação Infantil tratam: da ampliação da oferta de creches e pré-escolas; da elaboração de padrões mínimos de qualidade de infraestrutura para o funcionamento adequado das instituições coletivas de Educação Infantil públicas e privadas; da autorização de funcionamento dessas instituições; da formação dos profissionais da área em universidades, institutos superiores de educação e organizações não-governamentais; do estabelecimento de programas de orientação e apoio aos pais com filhos menores de três anos; da implantação de conselhos escolares e outras formas de participação da comunidade local; da garantia da alimentação escolar para crianças atendidas em estabelecimentos públicos e conveniados; do fornecimento de materiais pedagógicos adequados às faixas etárias; do estabelecimento de padrões de qualidade como referência para a supervisão, o controle, a avaliação e o aperfeiçoamento da Educação Infantil, entre outros aspectos. (BRASIL, 2014)

O acompanhamento da evolução dessas metas ou objetivos pode ser feito por meio do observatório do Plano Nacional de Educação, disponível na página do MEC. Quanto à matrícula de crianças em creches e pré-escola, o Plano prevê, como meta, 50\% das crianças na faixa etária de 0 a 3 anos. No entanto, o percentual é de 30,4\%. Para a faixa etária de 4 a 5 anos, o Plano prevê que todas as crianças com idade entre 4 a 5 anos devem estar matriculadas na pré-escola, mas o percentual, até o ano de 2015, foi de $80,1 \%$ (BRASIL, 2014).

A análise que se faz, neste estudo, é que, desde a promulgação da Constituição Federal de 1988, existe a ideia de uma base curricular comum às escolas de todo país. No Art. 210, fica evidenciado que: "Serão fixados conteúdos mínimos para o ensino fundamental, de maneira a assegurar formação básica comum e respeito aos valores culturais e artísticos, nacionais e regionais" (BRASIL, 1988, não paginado).

Nesse viés, no ano de 2017, foi aprovada, no Conselho Nacional de Educação, a Base Nacional Comum Curricular (BNCC), objetivando unificar as influências e as referências de cada instituição de ensino. A BNCC pretende solucionar um problema comum no Brasil. Quando se analisam os currículos escolares espalhados pelo país, é possível encontrar discrepâncias entre os conteúdos no Ensino Fundamental, como, por exemplo, na Disciplina de Língua Portuguesa. Isso pode ser percebido na medida em que existem conteúdos que devem se utilizar de recursos linguísticos e semióticos, com o objetivo de facilitar a alfabetização/letramento (BRASIL, 2017).

Todavia, percebem-se divergências a respeito da alfabetização de crianças no primeiro ano do Ensino Fundamental. Em determinadas escolas, ao final do primeiro ano, a maioria das crianças sabem ler, escrever e interpretar o mundo de acordo com suas vivências. Em outras, por sua vez, as crianças permanecem no processo de alfabetização/letramento durante os três primeiros anos escolares. A BNCC é um documento que visa nortear o que deve ser ensinado nas escolas brasileiras, englobando todas as fases da Educação Básica, desde a Educação Infantil até o Ensino Fundamental.

A BNCC (BRASIL, 2017) dá a abertura para a elaboração de um currículo específico de cada escola, sem desconsiderar as particularidades metodológicas, sociais e regionais de cada uma. Isso significa que a Base estabelece os objetivos de aprendizagem que se quer alcançar, por meio da definição de competências e de habilidades essenciais, enquanto o currículo determinará como esses objetivos serão alcançados, traçando as estratégias pedagógicas mais adequadas.

Nessa perspectiva, as instituições que trabalham com Educação Infantil deverão reconstruir seus Projetos Políticos Pedagógicos pautados nos direitos de aprendizagem e nos campos de experiências, respeitando as idades descritas na BNCC. Para tanto, é importante considerar outros três pontos destacados nesse documento: a intencionalidade educativa, o monitoramento das práticas pedagógicas 
MARCOS REGULATÓRIOS E AS IMPLICAÇÕES NA ORGANIZAÇÃO RODRIGUES, J. S. M.; BOER, N.; MARQUEZAN, F.

e o acompanhamento da aprendizagem e do desenvolvimento da criança (BRASIL, 2017).

O primeiro ponto, a intencionalidade educativa, refere-se à orientação da criança para se alimentar, vestir-se, higienizar-se, brincar, desenhar, pintar, recortar, conviver com livros e escutar histórias; além de suas orientações para realizar experiências, resolver conflitos e trabalhar com os outros. Esse processo exige do docente o monitoramento das práticas pedagógicas (segundo ponto), que se fundamenta na observação sistemática do efeito e do resultado de suas ações para as aprendizagens e o desenvolvimento das crianças, a fim de aperfeiçoar ou de corrigir suas práticas se for necessário. $\mathrm{O}$ terceiro ponto, o acompanhamento da aprendizagem e do desenvolvimento das crianças, deve ser realizado por meio de diversos registros, feitos tanto pelo professor, quanto pelas crianças, sem a intenção de seleção, de promoção ou de classificação.

Nesse sentido, o desafio das instituições que contemplam a Educação Infantil consiste em colocar em prática as orientações propostas pela BNCC para o desenvolvimento integral da criança. Nessa perspectiva, torna-se relevante a construção de diálogos entre os professores, pesquisadores e a comunidade escolar, para a (re)elaboração das propostas pedagógicas relacionadas a essa etapa formativa. Ressalta-se que a implementação de um currículo passa por uma reflexão crítica dos docentes a respeito de suas práticas e concepções. Esse movimento é necessário para incorporar as orientações da BNCC que façam sentido no seu cotidiano de trabalho.

O Quadro 1, a seguir, apresenta uma síntese dos marcos regulatórios na Educação Infantil descritos nessa seção.

Quadro 1 - Síntese dos marcos regulatórios curriculares na Educação Infantil

\begin{tabular}{|c|l|}
\hline $\begin{array}{c}\text { MARCOS } \\
\text { REGULATÓRIOS } \\
\text { CURRICULARES }\end{array}$ & \multicolumn{1}{c|}{ ORIENTAÇÕES } \\
\hline RCNEI (1998) & $\begin{array}{l}\text { A elaboração da proposta curricular de cada instituição se constitui em um dos } \\
\text { elementos do projeto educativo e deve ser fruto de um trabalho coletivo, o qual } \\
\text { reúna professores, demais profissionais e técnicos. Outros aspectos são relevantes } \\
\text { para o bom desenvolvimento do projeto pedagógico e devem ser considerados, } \\
\text { abrangendo desde o clima institucional, as formas de gestão, passando pela } \\
\text { organização do espaço e do tempo, dos agrupamentos, seleção e oferta dos } \\
\text { materiais, até a parceria com as famílias e o papel do professor. }\end{array}$ \\
\hline DCNEI (2009) & $\begin{array}{l}\text { O conjunto de práticas que buscam articular as experiências e os saberes das } \\
\text { crianças com os conhecimentos que fazem parte do patrimônio cultural, artístico, } \\
\text { ambiental, científico e tecnológico, de modo a promover o desenvolvimento } \\
\text { integral de crianças de o a 5 anos de idade. }\end{array}$ \\
\hline BNCC (2017) & $\begin{array}{l}\text { O objetivo de ampliar o universo de experiências, conhecimentos e habilidades } \\
\text { dessas crianças, diversificando e consolidando novas aprendizagens, atuando de } \\
\text { maneira complementar à educação familiar - especialmente quando se trata da } \\
\text { educação dos bebês e das crianças bem pequenas, que envolve aprendizagens } \\
\text { muito próximas aos dois contextos (familiar e escolar), como a socialização, a } \\
\text { autonomia e a comunicação. }\end{array}$ \\
\hline
\end{tabular}

Fonte: Organizado pelas autoras.

Com base no exposto nesta seção, nota-se que o ordenamento legal e os estudos realizados, a respeito da Educação Infantil, avançaram no período de 1990 a 2000, sobretudo, no sentido de considerar a criança como sujeito de direitos, que tem expressões de singularidade, de sociabilidade, de historicidade e de cultura. Portanto, a criança deverá ter garantia de seu desenvolvimento integral, por meio da educação que recebe em creches e pré-escola. Nisso, reside a importância de um currículo concebido como um conjunto de práticas que articulam as experiências e os saberes das crianças com os 
conhecimentos que fazem parte do patrimônio cultural, artístico, ambiental e tecnológico, em um ambiente capaz de articular práticas de educação e cuidado, conforme dispõem as diretrizes nacionais para a Educação Infantil.

\section{ORGANIZAÇÃO DO CURRÍCULO NA EDUCAÇÃO INFANTIL}

A organização do currículo, na Educação Infantil, apresenta concepções contraditórias, tendo em vista que alguns especialistas discordam quanto à necessidade de organizar conteúdos para trabalhar na Educação Infantil. Em vista disso, torna-se importante a reflexão relativa à organização curricular, na medida em que se perscruta o escape ao assistencialismo, bem como o caráter compensatório vivido, durante anos, pelas crianças.

Na concepção de Viera e Garms (2015), autores como Craidy (2002), Guimarães e Garms (2012), Kuhlmann Júnior e Fernandes (2012) e Fullgraf (2012) apontam que o fato de a Educação Infantil ter sido inserida no sistema educacional, recentemente, não fez com que esse nível de ensino se transformasse em instituição educativa. Para esses estudiosos, creches e pré-escola sempre foram instituições educativas, uma vez que não é possível educar sem cuidar e vice-versa. Concordam, igualmente, que o desafio posto às instituições de Educação Infantil é construir propostas pedagógicas/curriculares para todos, fundadas na Pedagogia da Infância, elementos esses que melhorariam a qualidade da educação nessa etapa escolar.

No Brasil, as principais ideias, relativas ao currículo na Educação Infantil, foram se alargando quando o MEC publicou a opinião de profissionais da área respondendo à questão: $O$ que é proposta pedagógica e currículo na Educação Infantil? (BRASIL, 1996b)

Conforme o relatório do MEC (BRASIL, 1996b), pesquisadores em educação infantil e currículo, como Kishimoto (1994), Oliveira (1994), Machado (1994), Mello (1994) e Kramer (1994), não chegaram a um consenso a respeito dos conceitos questionados pelo Ministério. Esses autores defendem que, no currículo, é preciso estarem explícitos valores e concepções de infância, homem, educação, educação infantil, conhecimento, cultura, desenvolvimento infantil, função da instituição em relação à criança, à família e à comunidade. Defendem, ainda, que aspectos institucionais/organizacionais e a natureza dinâmica e aberta precisam ser considerados no currículo (VIEIRA; GARMS, 2015).

Na tentativa de identificar a compreensão de currículo para a Educação Infantil, foram consultados referencias de diferentes matrizes teóricas, bem como marcos regulatórios que normatizam as políticas públicas para a Educação Infantil e, consequentemente, o currículo para essa etapa da Educação Básica. Viera e Garms (2015) apresentam uma ampla abordagem das concepções de currículo para a Educação Infantil. Essas podem ser visualizadas no Quadro 2.

Quadro 2: Concepções norteadoras de currículo

\begin{tabular}{|l|l|}
\hline \multicolumn{1}{|c|}{ AUTORES } & \multicolumn{1}{c|}{ CONCEPÇÃo DE CURRícULO } \\
\hline $\begin{array}{l}\text { Oliveira (2010), Guimarães e Garms (2012), } \\
\text { Amorim e Dias (2012) e Wiggers (2012) }\end{array}$ & $\begin{array}{l}\text { [...] o currículo gera muitas discussões, no momento em } \\
\text { que é concebido, na Educação Infantil, como uma } \\
\text { preparação aos anos iniciais do Ensino Fundamental, } \\
\text { apresentando-se como um conjunto de disciplinas e de } \\
\text { conteúdos. }\end{array}$ \\
\hline Lins e Diniz (2012, p.10) & $\begin{array}{l}\text { [...] o currículo é considerado espaço de construção de } \\
\text { subjetividades e lócus de materialização/apreensão de } \\
\text { concepções de infância e educação". }\end{array}$ \\
\hline
\end{tabular}




\begin{tabular}{|l|l|}
\hline Pérez (2013, p.347) & $\begin{array}{l}{[\ldots] \text { o currículo, na Educação Infantil, deve levar em }} \\
\text { conta, de forma organizada e sistemática, a totalidade } \\
\text { de atividades e experiências de aprendizagem das quais } \\
\text { o aluno deve ser o protagonista, sob a tutela e } \\
\text { responsabilidade direta as escolas [...] }\end{array}$ \\
\hline Oliveira (2010, p.4) & $\begin{array}{l}{[\ldots] \text { formas de organização do cotidiano das unidades de }} \\
\text { educação infantil, cujo fim está na promoção do } \\
\text { desenvolvimento das crianças e foge da ideia de } \\
\text { conteúdos de disciplinas fragmentadas. }\end{array}$ \\
\hline Guimarães e Garms (2012, p. 16) & $\begin{array}{l}{[\ldots] \text { onde está registrado um programa de atividades }} \\
\text { específicas, cujas intencionalidades estejam delineadas } \\
\text { com clareza e com base em ações e interações entre } \\
\text { crianças e seus pares e crianças e adultos". }\end{array}$ \\
\hline
\end{tabular}

Fonte: As autoras, adaptado de Viera e Garms (2015).

A partir da análise do Quadro 2, percebe-se que, entre os documentos oficiais, o único que estabelece, claramente, a concepção de currículo, para a Educação Infantil, são as DCNEI (BRASIL, 2009). Os demais documentos, RCNEI (BRASIL, 1998) e BNCC (BRASIL, 2017), apresentam uma ideia geral de currículo, o que dificulta uma compreensão mais precisa do que esses documentos preconizem a respeito do currículo para essa etapa da Educação Básica.

Como é possível acompanhar, no Quadro 2, as orientações curriculares adotadas no RCNEI (BRASIL, 1998) partiram de uma pesquisa com professores que atuavam na Educação Infantil, os quais buscavam considerar as práticas e o cotidiano das instituições, tendo em vista que, até o momento, não existia um documento oficial, que regulamentasse essa prática.

No que se refere à BNCC (BRASIL, 2017), nota-se que as orientações curriculares foram elaboradas a partir do primeiro documento que definiu o que é currículo na Educação Infantil, ou seja, as DCNEI (BRASIL, 2009). Quanto aos autores que escrevem sobre Educação Infantil, Oliveira (2010) busca fugir da ideia de conteúdos fragmentados e visa à promoção do desenvolvimento integral da criança, corroborando com os conceitos explícitos nas DCNEI.

Outra interpretação possível está na concepção de currículo descrita por Lins e Diniz (2012). Esses autores definem as compreensões necessárias aos docentes que atuam nessa etapa, destacando que o lugar de materialização e de apreensão das concepções de infância e educação são primordiais para o trabalho pedagógico na Educação Infantil.

Já no que toca à conceptualização de currículo por Pérez (2013), a criança é considerada protagonista. Entretanto, considerando-se a ênfase do autor para as palavras "organizada" e "sistemática", pode-se perceber que há uma fragilidade no conceito de currículo, tendo em vista que, para a criança ser realmente protagonista de suas ações, é necessário flexibilidade e autonomia curriculares. Na concepção de currículo identificada em Guimarães e Garms (2012), a diferença desse conceito está na intencionalidade dos "conteúdos expostos no programa”, os quais deverão ser descritos com clareza, levando em consideração as ações e as interações entre os partícipes do processo de ensinoaprendizagem na Educação Infantil.

Nesse ponto, cabe ressaltar que a prática profissional da primeira autora deste artigo sinaliza que, para haver aprendizagem, é preciso organizar um currículo que seja significativo às crianças e, também, ao professor. Dessa forma, entende que o currículo é vivo, é ação, é prática que se manifesta no cotidiano da sala de aula. As atividades desenvolvidas com as crianças se articulam com quem elas são, como o que pensam, o que sabem, com aquilo que se deseja que elas aprendam (RODRIGUES; BOER, 2019).

Para transpor, de forma didática, o currículo da Educação Infantil, os Projetos Pedagógicos abrem para as possibilidades de aprendizagem de diferentes conhecimentos construídos na história da humanidade. Conhecimentos organizados de modo relacional e não-linear propiciam às crianças 
aprenderem por meio de múltiplas linguagens, ao mesmo tempo que lhes permitem a reconstrução daquilo que já foi aprendido (BARBOSA; HORN, 2008).

Nessa linha de raciocínio, é necessário redimensionar a concepção de currículo, ultrapassando a ideia de programa escolar, com listas intermináveis de conteúdos fragmentados, obrigatórios e uniformes. Um currículo que se constrói por meio de um percurso educativo orientado não ser fechado ou pré-definido em sua integralidade (BARBOSA; HORN, 2008). Segundo essas autoras, "Construir um currículo a partir de pistas do cotidiano e de uma visão articulada de conhecimento é fundamental. $O$ currículo não pode ser definido previamente, precisando emergir e ser elaborado em ação, na relação entre o novo e a tradição" (p.37).

Outros pontos importantes de serem considerados, na organização das propostas pedagógicas/curriculares, são: o espaço, o tempo e os materiais necessários para o fazer pedagógico na Educação Infantil. Assim, espaço e tempo se organizam com o objetivo de oferecer possibilidades de agir e de experimentar, sozinho e com outros, jogando, brincando, imaginando e criando. Desse modo, o espaço físico se organiza para favorecer a interação com o outro e com os objetos. Já a rotina diária, precisa oferecer segurança e estruturar as ações da criança no tempo de permanência na creche/préescola, sem ser rotineira ou desprovida de sentido.

Assim, uma proposta curricular que tenha como intuito promover uma aprendizagem significativa necessita encontrar as interrogações nos percursos que as crianças fazem. Com isso, é fundamental permitir que se envolvam com experiências e vivencias complexas, as quais, justamente, instiguem sua curiosidade. Nessas situações, é importante [res]significar as diferentes formas de interpretar, representar e simbolizar tais vivências, seja por meio do desenho, da expressão corporal, seja pelo contato com diferentes materiais. "A autonomia moral e intelectual são consideradas princípios básicos das propostas e das interações com a criança” (GUIMARÃES; GARMS, 2012, p.57).

Todavia, o diagnóstico realizado pelo MEC e divulgado em 1996 demonstrou que, entre os principais problemas identificados nas propostas pedagógicas/curriculares analisadas, estão: a falta de clareza e de consistência em certas concepções; a insuficiente descrição da clientela e de como as propostas atendem às suas características; a pouca explicação das estratégias de implementação dessas propostas (BRASIL, 1996b).

Passadas mais de duas décadas do referido diagnóstico, é possível observar que os problemas listados pelo MEC, em 1996, continuam sendo uma fragilidade na especificidade da Educação Infantil. Desse modo, evidenciam-se desafios na organização de propostas pedagógicas para a Educação Infantil, como a dificuldade de viabilizar uma maior participação dos professores no processo de elaboração das propostas pedagógicas. Ainda, identificam-se lacunas na formação inicial e continuada dos professores da Educação Infantil para transformar em prática os pressupostos estabelecidos nos documentos regulatórios. De acordo com Goulart (2007):

Precisamos é de uma nova formação docente, que garantirá a continuidade da educação no coletivo das crianças de todas as idades. O compromisso com o conhecimento, produto da formação cientifica e artística na docência para a infância, favorecerá a construção de uma pedagogia capaz de formar o cidadão de pouca idade centrada em ações integradoras do ser, tais como o brincar, ação humana em que o pensar e o fazer podem não estar dissociados, desde que a intencionalidade educativa do adulto profissional assim o deseje (GOULART, 2007, p. 9).

Corrobora-se essa afirmação, porque é na primeira infância que as estruturas básicas de pensamento são construídas. É nesse período que se iniciam os mecanismos de interação com o ambiente e são elaboradas a identidade social e pessoal. "A intencionalidade educativa das propostas pedagógicas é determinante no trabalho do professor" (ARRIBAS, 2004, p.15), e essa deve estar explicitada no currículo que orienta o fazer cotidiano e educativo da Educação Infantil. Isso significa vincular "[...] o lúdico ao educativo, que entenda o pedagógico como cultural, que desconstrua a ideia de aluno, de aula e conceba o sujeito-criança, num espaço de convívio coletivo, onde as mais diversas interações possam 
estabelecer-se" (CORSINO, 2009, p.10).

Dessa maneira, urge tornar as discussões sobre o currículo da Educação Infantil uma tarefa a ser enfrentada a partir de pressupostos que a política de atendimento à criança pequena orienta. É preciso delimitar o que é específico dessa etapa educacional: cuidar e educar integradamente, em um ambiente que considera as necessidades e os interesses próprios da faixa etária, tais como a movimentação do corpo, a brincadeira, a interação com adultos e pares, a expressão e a representação, nas suas diferentes modalidades; a ampliação de seu conhecimento do mundo natural e social, o acesso à cultura, a tempos, espaços e materiais que promovam desenvolvimento intelectual, motor, afetivo, social, dentre outros. Todos esses aspectos estão descritos nos marcos regulatórios já mencionados.

Tendo em vista que a criança desenvolve suas estruturas mentais a partir das ações que desenvolve no ambiente e na interação com outras pessoas, a Educação Infantil requer uma proposta pedagógica a qual contemple o plano orientador das ações da instituição, defina as metas que se pretende alcançar no desenvolvimento das crianças que nela são educados e cuidados, bem como as aprendizagens que necessitam ser promovidas. Portanto, a instituição organiza seu currículo, que pode ser compreendido como as práticas educacionais organizadas em torno do conhecimento e em meio às relações sociais que se entrecruzam nos espaços institucionais, as quais afetam a construção da identidade das crianças.

\section{CONSIDERAÇÕES FINAIS}

Diante do exposto, pode-se concluir que os marcos regulatórios que normatizam a Educação Infantil servem de parâmetros para o desenvolvimento de ações de fortalecimento da educação nesse nível de ensino. Ademais, contribuem para a efetivação do direito da criança à educação na primeira infância, promovendo sua inclusão social e democratizando o acesso à educação com qualidade.

O objetivo das políticas para a Educação Infantil é garantir a ampliação da oferta de creches para a população de até três anos de idade, oferecendo, às crianças, uma educação de maior equidade e qualidade nesse período de desenvolvimento. Tais políticas precisam estar orientadas de modo a atuar sobre a infraestrutura das creches e das escolas de Educação Infantil, à formação continuada de profissionais, e na articulação interinstitucional da gestão em âmbito global (nacional e municipal) e local (escola).

Portanto, é de se esperar que, diante dos marcos regulatórios e das políticas públicas que normatizam a Educação Infantil, na esfera nacional, nos Estados e municípios brasileiros, que se contribua para a efetiva qualidade da educação de crianças de zero a cinco anos. Isso não isenta professores e a família da responsabilidade de conhecer as políticas públicas da Educação Infantil para exigi-las junto aos poderes constituídos. Só assim, será possível acompanhar o desenvolvimento das crianças, nas escolas, e certificar-se de que essas instituições estejam cumprindo o princípio de cuidar e de educar, possibilitando a aprendizagem dos pequenos.

\section{REFERÊNCIAS}

ABRAMOVAY, Miriam; KRAMER, Sonia. “O rei está nu”: um debate sobre as funções da pré-escola. Cadernos CEDES, São Paulo, Cortez, n. 9, p. 27-38, 1984.

AMORIN, Ana Luisa Nogueira de.; DIAS, Adelaide Alves. Currículo e Educação infantil: uma análise dos documentos curriculares nacionais. Rev. Espaço do Currículo, João Pessoa, v.4, n.2, p. 125-137, 2012.

Disponível em: http://periodicos.ufpb.br/ojs/index.php/rec/article/view/12330/7106. Acesso em: 26 jun. 2017.

AQUINO, Lígia Maria leão de; VASCONCELLOS, Vera Maria Ramos de. Orientação curricular para a Educação Infantil: Referencial Curricular Nacional e Diretrizes Curriculares Nacionais. In:

VASCONCELLOS, Vera Maria Ramos de (org.). Educação da Infância: história e política. Niterói, RJ: Eduff, 2005. p. $15-25$.

ARRIBAS, Teresa Lleixa. (org.). Educação infantil-desenvolvimento, currículo e organização escolar. 5. ed. Porto Alegre: Artmed, 2004. 
ISSN 1983-1579

Doi: 10.22478/ufpb.1983-1579.2020v13n1.41599

http://periodicos.ufpb.br/ojs2/index.php

BARBOSA, Maria Carmem Silveira; HORN, Maria da Graça Souza. Projetos pedagógicos na educação infantil. Porto Alegre: Artmed, 2008.

BRASIL. Ministério da Educação e Saúde. Lei número 4.024, de 20 de dezembro de 1961. Fixa as Diretrizes e Bases da Educação Nacional. Diário Oficial da União, Brasília, DF, 27 dez. 1961.

BRASIL. Ato institucional $n^{\circ}$, de 13 de dezembro de 1968. Disponível em: http://www.planalto.gov.br/CCIVil_03/AIT/ait-05-68.htm. Acesso em: 22. jul. 201.

BRASIL. Ministério da Educação e Saúde. Lei número 5.692, de 11 de agosto de 1971. Fixa as Diretrizes e Bases para o ensino de $1^{\circ}$ e $2^{\circ}$ graus, e dá outras providências. Diário Oficial da União, Brasília, DF, 18 ago. 1971.

BRASIL. Constituição da República Federativa do Brasil (1988). Brasília, DF: Senado Federal, 1988. Disponível em: http://www.planalto.gov.br/ccivil_03/constituicao/constituicao.htm. Acesso em: 26 maio. 2017.

BRASIL. Lei n. 8.069 de 13 de julho de 1990. Dispõe sobre o Estatuto da Criança e do Adolescente. Disponível em: http://www.planalto.gov.br/ccivil_03/leis/l8069.htm. Acesso em: 25 maio. 2017.

BRASIL. Conselho Nacional de Educação. Lei n. 9.394 de 20 de dezembro de 1996. Estabelece as Diretrizes e Bases da Educação Nacional. Diário Oficial [da] República Federativa do Brasil. Brasília, DF, 23 dez. 1996a.

BRASIL. Ministério da Educação. Propostas pedagógicas e currículo em educação infantil: um diagnóstico e a construção de uma metodologia de análise. Brasília, DF: MEC/SEF/DPE/COEDI, $1996 \mathrm{~b}$.

BRASIL. Ministério da Educação e do Desporto. Secretaria de Educação Fundamental. Subsídios para o Credenciamento e Funcionamento das Instituições de Educação Infantil. Brasília, DF: MEC/SEF/DPE/COEDI, 1998 a.

BRASIL. Ministério da Educação e do Desporto. Secretaria de Educação Fundamental. Referencial Curricular Nacional para a Educação Infantil. Brasília, DF: MEC/SEF, 1998b. v.1. Disponível em: http://portal.mec.gov.br/seb/arquivos/pdf/rcnei_vol1.pdf. Acesso em: 6 jun. 2017.

BRASIL. Ministério da Educação e do Desporto. Secretaria de Educação Fundamental. Referencial Curricular Nacional para a Educação Infantil. Brasília, DF: MEC/SEF, 1998b. v.2. Disponível em: http://portal.mec.gov.br/seb/arquivos/pdf/volume2.pdf. Acesso em: 10 jun. 2017.

BRASIL. Ministério da Educação e do Desporto. Secretaria de Educação Fundamental. Referencial Curricular Nacional para a Educação Infantil. Brasília, DF: MEC/SEF, 1998d. v.3 Disponível em: http://portal.mec.gov.br/seb/arquivos/pdf/volume3.pdf. Acesso em: 5 jun.2017.

BRASIL. Lei no 10.172, de 09 de janeiro de 2001. Aprova o Plano Nacional de Educação. Brasília-DF. Disponível em: http://www.planalto.gov.br/ccivil_03/leis/leis_2001//10172.htm. Acesso em: 17 mai. 2017

BRASIL. Ministério da Educação. Secretaria de Educação Básica. Diretrizes Curriculares Nacionais para a Educação Infantil. Secretaria de Educação Básica. Brasília: MEC, SEB, 2010.

BRASIL. Lei $n^{\circ} 12.796$ de 4 de abril de 2013. Altera a Lei no 9.394, de 20 de dezembro de 1996, que estabelece as diretrizes e bases da educação nacional, para dispor sobre a formação dos profissionais da educação e dar outras providências. Disponível em: http://www.planalto.gov.br/ccivil_03/_atozo112014/2013/lei/l12796.htm . Acesso em: 14 out. 2019.

BRASIL. Lei no 13.005, de 25 de junho de 2014. Aprova o Plano Nacional de Educação. Brasília-DF. Disponível em: http://www.planalto.gov.br/ccivil_03/_ato2011-2014/2014/lei/l13005.htmAcesso em: 17 maio 2017.

BRASIL. Ministério da Educação. Base Nacional Comum Curricular. Brasília: MEC, 2017. Disponível em: http://basenacionalcomum.mec.gov.br/wp-content/uploads/2018/02/bncc-2odez-site.pdf. Acesso em: 18 dez. 2017. 
MARCOS REGULATÓRIOS E AS IMPLICAÇÕES NA ORGANIZAÇÃO RODRIGUES, J. S. M.; BOER, N.; MARQUEZAN, F.

CORRÊA, Bianca Cristina. A educação infantil. In: OLIVEIRA, Romualdo Portela de.; ADRIÃO, Thereza. (Org.). Organização do ensino no Brasil: níveis e modalidades na Constituição Federal e na LDB. São Paulo: Xamã, 2002. p. 13-32.

CORSINO, Patrícia (org.). Educação infantil: quotidiano e políticas. Campinas, SP: Autores Associados, 2009.

CRAIDY, Carmem Maria. A educação da criança de 0 a 6 anos: o embate assistência e educação na conjuntura nacional e internacional. In: MACHADO, Maria Lucia de A. (org.) Encontros e desencontros em Educação Infantil. 2. ed. São Paulo: Cortez, 2002.

FAZENDA, Ivani Catarina Arantes. (org.). Encontros e Desencontros da Didática e da Prática de Ensino. São Paulo: Cortez, 1988.

FULLGRAF, Jodete Bayer Gomes. Política de Educação Infantil no Brasil. In: FLÔR, Dalânea Cristina.; DURLI, Zenilde. (org.), Educação infantil e formação de professores. Florianópolis, SC: UFSC, 2012. p. 5977.

GOULART, Ana Lucia de Faria. Para uma Pedagogia da infância. Pátio Educação Infantil, Porto Alegre, ano 5, p. 6-0, jul./out. 2007.

GUIMARÃES, Célia Maria.; GARMS, Gilza Maria Zauhy. Implicações da Política Nacional de Educação Infantil para o currículo da creche/pré-escola. In: JEFFREY, Débora Cristina.; AGUILAR, Luis Enrique. (org.). Política Educacional Brasileira: análise e entraves. Campinas, SP. Mercado de Letras, 2012. p. 9-14.

KISHIMOTO, Tizuko Morchida. Currículo de educação infantil: creches e pré-escolas. Significado do termo currículo. Currículo de educação infantil: critérios de qualidade e instrumentos de implementação. Texto encomendado pela Coordenação-Geral de Educação Infantil do MEC. Dezembro. 1994 (mimeo).

KRAMER, Sônia. Propostas pedagógicas de educação infantil: subsídios para uma leitura crítica. Texto encomendado pela Coordenação Geral de Educação Infantil do MEC, em novembro de 1994 (mimeo).

KUHLMANN JÚNIOR, Moysés.; FERNANDES, Fabiana Silva. Infância: construção social e histórica. In: VAZ, Alexandre Fernandez.; MOMM, Caroline Machado. Educação infantil e sociedade: questões contemporâneas. Nova Petrópolis, SC: Nova Harmonia, 2012. p. 21-39.

LINS, Heloísa Andréia de Matos; DINIZ, Neusa Lopes Bispo. Repensar o currículo na educação infantil: implicações sobre o brincar e a língua(gem). Campinas, SP: Silvamartin Leitura Crítica, 2012.

MACHADO, M.L de A. Proposta de critérios de análise e avaliação de projetos educacionais-pedagógicos para a educação infantil no Brasil. Versão preliminar. São Paulo, dezembro, 1994 (mimeo).

MELLO. Ana Maria. Reflexões sobre proposta pedagógica e currículo. Texto encomendado pela Coordenação Geral de Educação Infantil. Dezembro, 1994 (mimeo).

OLIVEIRA, Zilma de Moraes Ramos de. Uma contribuição ao debate promovido pela Coordenação Geral de Educação Infantil do Ministério da Educação e do Desporto acerca da Análise e Avaliação de Propostas Pedagógicas Implementadas nas Creches e Pré-escolas Públicas Brasileiras, visando oferecer uma cooperação técnica aos estados e municípios. Dezembro, 1994 (mimeo).

OLIVEIRA, Zilma de Moraes Ramos de. O currículo na Educação Infantil: O que propõem as novas Diretrizes Nacionais? In: SEMINÁRIO NACIONAL: CURRÍCULO EM MOVIMENTO, 1., 2010, Belo Horizonte. Anais [...]. Belo Horizonte, 2010. p. 1-14. Disponível em: http://portal.mec.gov.br/docman/dezembro2010-pdf/7153-2-1-curriculo-educacao-infantil-zilma-moraes/file. Acesso em: 23 nov. 2017.

PEREZ, Justa Bejarano. O currículo na educação infantil. In: SACRISTÁN, José Gimeno. Saberes e incertezas sobre o currículo. Porto Alegre: Penso, 2013. p. 336-354.

RODRIGUES, Joseane da Silva Miller; BOER, Noemi. Da epistemologia à prática docente na educação infantil: relato de uma sequência didática. Res., Soc. Dev, v.8, n. 6, p. 1-17, 2019. DOI:

http://dx.doi.org/10.33448/rsd-v8i6.969 
ISSN 1983-1579

Doi: 10.22478/ufpb.1983-1579.2020v13n1.41599

http://periodicos.ufpb.br/ojs2/index.php

ROMANELLI, Otaíza de Oliveira. História da educação no Brasil (1930/1973). 28.ed. Petrópolis, RJ: Vozes, 2003.

ROSEMBERG, Fúlvia. Organizações multilaterais, estado e políticas de educação infantil. Cadernos de Pesquisa, São Paulo, n. 115, p. 25-63, mar. 2002.

VIEIRA, Izabel Carvalho da Silva; GARMS, Gilza Maria Zauhy. A relação cuidar e educar presente na proposta pedagógica/currículo da creche 2015. Disponível em:

http://www.marilia.unesp.br/Home/Eventos/2015/jornadadonucleo/a-relacao-cuidar-e-educar.pdf. Acesso em: 13 abr. 2018.

WIGGERS, Verena. Currículo na educação infantil. In: FLÔR, Dalânea Cristina; DURLI, Zenilde (org.). Educação infantil e formação de professores. Florianópolis, SC: UFSC, 2012. cap. 4, p. 79-95.

Recebido em: 30 de agosto de 2018 Aceito em: 02 de dezembro de 2019

Publicado em: 25 de abril de 2020 